\title{
Caveolin-1 and dynamin-2 overexpression is associated with the progression of bladder cancer
}

\author{
SADAF AZAD RAJA $^{1}$, SYED TAHIR ABBAS SHAH ${ }^{1}$, AAMIRA TARIQ $^{1}$, NAZIA BIBI ${ }^{1}$, \\ KALSOOM SUGHRA ${ }^{2}$, ARZU YOUSUF ${ }^{3}$, ATHAR KHAWAJA ${ }^{3}$, MUHAMMAD NAWAZ ${ }^{4}$, \\ ARSHAD MEHMOOD $^{4}$, MUHAMMAD JADOON KHAN ${ }^{1}$ and ALAMDAR HUSSAIN ${ }^{1}$ \\ ${ }^{1}$ Department of Biosciences, COMSATS University Islamabad, Islamabad 45550; ${ }^{2}$ Department of Biochemistry \\ and Biotechnology, University of Gujrat, Gujrat 50700; ${ }^{3}$ Department of Urology and Kidney Transplant, \\ Shifa International Hospital, Islamabad 44790; ${ }^{4}$ Armed Forces Institute of Urology, Rawalpindi 46000, Pakistan
}

Received September 14, 2018; Accepted April 3, 2019

DOI: $10.3892 / \mathrm{ol} .2019 .10310$

\begin{abstract}
Caveolae-mediated endocytosis regulates cell adhesion and growth in an anchorage-dependent manner. Studies of the endocytic function of caveolae have suggested a wide-ranging list of cargoes, including a number of receptors and extracellular proteins, ligands and nutrients from the extracellular matrix. Disruption of the processes of caveolae-mediated endocytosis mediated by signaling proteins is critical to cellular integrity. Caveolin-1 and dynamin-2 are the 2 major proteins associated with endocytotic function. Mechanistically, dynamin-2 has a co-equal role with caveolin-1 in terms of caveolae-derived endosome formation. Recent studies have revealed the pathological outcomes associated with the dysregulation of caveolin-1 and dynamin-2 expression. Increased expression levels of the gene for caveolin, Cav-1, resulting in augmented cellular metastasis and invasion, have been demonstrated in various types of cancer, and overexpression of the gene for dynamin-2, DNM2, has been associated with tumorigenesis in cervical, pancreatic and lung cancer. An increased expression of $C a v-1$ and DNM2 is known to be associated with the invasive behavior of cancer cells, and with cancer progression. Furthermore, it has been previously demonstrated that, in caveolar assembly and caveolae mediated endocytosis, $\mathrm{Cav}-1$ interacts directly with DNM2 during the processes. Altered expression of the 2 genes is critical for the normal function of the cell. The expression patterns of $C a v-1$ and DNM2 have been previously examined in bladder cancer cell lines, and were each demonstrated to be overexpressed. In the present study, the expression levels of these 2 genes in bladder cancer samples were quantified.
\end{abstract}

Correspondence to: Dr Syed Tahir Abbas Shah, Department of Biosciences, COMSATS University Islamabad, 110 Academic Block III, COMSATS University Islamabad, Park Road, Chak Shahzad, Tarlai Kalan, Islamabad 45550, Pakistan

E-mail: syedtahirabbas@comsats.edu.pk

Key words: bladder cancer, caveolin-1, dynamin-2
The gene expression levels of Cav-1 and DNM2 were identified to be increased 8.88- and 8.62-fold, respectively, in tumors compared with the normal controls. Furthermore, high-grade tumors exhibited significantly increased expression levels of Cav-1 and DNM2 (both $\mathrm{P}<0.0001$ ) compared with the low-grade tumors. In addition, compared with normal control samples, the expression of the 2 genes in tumor samples was observed to be highly significant $(\mathrm{P}<0.0001)$, with a marked positive correlation identified for the tumors (Pearson's correlation coefficient, $r=0.80$ for the tumor samples vs. $r=0.32$ in the normal control samples). Taken together, the results of the present study demonstrated that the overexpression of $\mathrm{Cav}-1$ and DNM2 genes, and a determination of their correlation coefficients, may be a potential risk factor for bladder cancer, in addition to other clinical factors.

\section{Introduction}

Caveolae are small bulb-like invaginations (50-80 $\mathrm{nm}$ in diameter) in the plasma membrane, with a diverse array of signal transduction functions (1-3). Functioning as a signal-transducing platform, caveolae are actively involved in the transcellular transport of ligands and receptor molecules, forming a specialized transporting system that maintains the lipid content of plasma membranes via transcytosis (4). Caveolae have been implicated as crucial entities for cell-cell communication via the endocytosis of signaling molecules, in addition to their role as signaling platforms where membrane receptors, including G-protein-coupled receptors, reside. Disrupted signaling through key caveolar proteins results in various pathologies, including cardiomuscular diseases, lipodystrophy, and, most importantly, cancer (5). Caveolar proteins exert their dynamic role in maintaining cell growth, cell protection and overall cell function (6). Caveolae consist of complexes comprising different transmembrane proteins, including caveolin, cavin, dynamin-2, EH-domain containing 2 protein and protein kinase $\mathrm{C}$ and casein kinase substrate in neurons protein 2 , among which caveolins are the core functional proteins (7). Cavins and caveolins (1-3) are the fundamental proteins that mediate caveolar organization. Caveolins provide a signaling platform for the coordination 
and interaction of different growth factor receptors, protein kinases and various intracellular signaling molecules (8). Dynamin-2, the product of the dynamin 2 (DNM2) gene, is a GTPase that directly interacts with caveolin-1, the product of the caveolin-1 (Cav-1) gene, mediating membrane scission, leading to endosome formation (9). Caveolin-1 and dynamin-2 are the key regulators of clathrin-independent endocytosis (10).

Among the caveolin proteins, caveolin-1 (molecular mass, $\sim 21 \mathrm{kDa}$ ) is known to be a key protein of the caveolae complex that has an important role in maintaining cell metabolism, anchorage-dependent growth, motility and signaling, and the cellular microenvironment (11). In fulfilling these crucial roles in cell growth and maintenance, the altered expression and function of caveolin-1 is associated with oncogenic cell transformation, cell metastasis, invasion and tumorigenesis. Enhanced expression of $\mathrm{Cav}-\mathrm{l}$ promotes tumor growth and invasion, resulting in the metastasis of human breast cancer cells (12). Knockdown of Cav-1 was demonstrated to inhibit tumor growth and metastasis (13). Dynamin-2 (molecular mass $\sim 100 \mathrm{kDa}$ ) is a GTPase that is actively involved in membrane fission during the endocytosis of cell-surface receptors and signaling molecules. The endosomes, also termed 'caveosomes', thus formed are continually recycled to the cell surface (14). This mechanism of protein expression on the cell membrane is disrupted in cancer cells. Dynamin-2 protein dysfunction results in the dysregulation of endosome recycling, causing an imbalanced expression of regulatory growth factor receptors, including epidermal growth factor receptor, on the cell surface, promoting aberrant cell growth, invasion and proliferation (15). Overexpression of Cav-1 and DNM2 has been demonstrated to be involved in cell lines of various types of cancer, including pancreatic, colon, lung, breast and prostate cancer $(13,16-22)$.

Bladder cancer is the ninth most common cancer worldwide. Of all incident cases of different types of cancer in the Pakistani population during the year $2012(n=148,041)$, the incidence rate of bladder cancer in the male population was 3,020 , which was increased compared with that in the female population $(n=946)$ (23). In muscle-invasive bladder cancers, 58 genetic mutations have been demonstrated to be causative factors for cancer progression in the bladder, and these are associated with low survival rates (24). There are a number of genetic alterations associated with bladder cancer progression. Overexpression, and genetic mutation, of several different genes that are critical in cell cycle regulation, apoptosis, signal transduction and angiogenesis have been identified, among which mutants of tumor protein (p53), fibroblast growth factor 3, Janus kinase/signal transducers and activator of transcription, hypoxia-inducible factor, retinoblastoma protein 1, HRas proto-oncogene, GTPase (also known as transforming protein p21), tuberous sclerosis 1, telomerase reverse transcriptase, and ubiquitin carboxyl-terminal hydrolase BAP1 have been identified and studied (24-26). Furthermore, numerous other previously identified genetic alterations are associated with a poor prognostic outcome, and these are currently undergoing validation (27). Regulatory genes that are involved in cell cycle regulation and apoptosis have been validated as combined prognostic markers for bladder cancer, although these are under investigation for use as single markers associated with urothelial carcinoma (28). However, genes/proteins that are involved in cell surface communication with the extracellular environment, cell-to-cell communication, endocytosis, and exocytosis are far more susceptible to cancer development compared with intercellular proteins, particularly caveolar proteins (29). The upregulation of caveolar proteins has been demonstrated for various different types of cancer, whereas only a few cancer types have been associated with their downregulation $(30,31)$. Despite the contradictory roles identified for caveolin-1 in different types of cancer, overexpression of Cav- 1 has been described for the majority of human cancer types. Previous studies investigating the overall clinical value of Cav-1, and its association with tumor aggressiveness, size, stage, grade and differentiation, suggest that it may serve as a good candidate prognostic marker for a majority of cancer types, including bladder cancer $(32,33)$. By contrast, the gene expression of $D N M 2$, and its association with cancer progression, has yet to be fully investigated. However, the identification and validation of the prognostic panel of disease markers for bladder cancer is required. A number of studies have explored the expression profiling of bladder cancer in humans, in which genome coding sequences were decoded for evaluating genetic alterations associated with the disease, and subsequently, the prognostic marker panel could be selected. However, one disadvantage in terms of ensuring its reproducibility is that this widely applied approach is highly expensive (34-36).

Bladder cancer, based on its metastatic ability to spread to other parts of the body, is divided into 4 stages (stages I-IV) according to the tumor-node-metastasis (TNM) staging system (37). Physiologically, bladder tumors are essentially categorized into 2 grades: Low-grade papillary urothelial carcinoma and high-grade papillary urothelial carcinoma, according to the World Health Organization/International Society of Urological Pathology classification system, published in 2004 (38). Previous studies have demonstrated altered expression levels of $C a v-1$ and DNM2 in bladder cancer cell lines $(33,39-41)$. Therefore, the present study aimed to investigate the degree of correlation of gene expression in comparing between the Cav-1 and DNM2 genes in bladder cancer tumor samples, specifically with respect to the progressiveness of the tumors. The results obtained revealed that the significant correlation between the overexpression of Cav-1 and DNM2 in bladder tumors was critical for cancer development, and for tumor stage and grade progression. The overexpression of these 2 genes could be considered clinically relevant and may prove as candidate risk factors for bladder cancer progression.

\section{Materials and methods}

Tumor sampling. The present study was approved by the Ethical Review Board of COMSATS University Islamabad (Islamabad, Pakistan; approval no. CIIT/Bio/ERB/18/76). Samples were collected between July, 2015 and March 2017. Tumor and normal tissue samples were excised from patients with bladder cancer post-surgery, following transurethral resection of bladder tumor (TURBT) surgery. Signed written consent was obtained from all the patients involved in the present study $(n=66$; male $=47$; female $=19)$. The patients' age ranged between 30 and 65 years and the median age was 43 years. The histopathological histories of the patients were confirmed by the Pathology Laboratory, Pakistan Institute of Medical Science (PIMS) (Islamabad, Pakistan) and Shifa International Hospital (Islamabad, Pakistan). Paired samples of tumors with their 
Table I. Primer sequence used for reverse transcription quantitative polymerase chain reaction analysis

\begin{tabular}{|c|c|c|c|c|}
\hline Transcript & Forward primer & Reverse primer & Length, bp & Primer location GRCh38.p12 \\
\hline Cav-1 & GACGTGGTCAAGAT & GACGAAATACTGGT & 120 & (Chr7: 116526678..116526689// \\
\hline (NM_001753.4) & TGACTTGA & TTTACCG & & $\begin{array}{l}\text { 116558946-116558956) } \\
\text { (Chr7: 116559032-116559053) }\end{array}$ \\
\hline$D N M 2$ & GCATGGGCACGCCA & GCTGCTGTCCCTGG & 119 & (Chr19: 10783083-10783102) \\
\hline (NM_001005360.2) & CATCTG & AGAAGGAG & & (Chr19: 10786623-10786644) \\
\hline
\end{tabular}

Cav-1, caveolin-1; DNM2, dynamin-2; chr, chromosome.

adjacent normal tissues were obtained. Normal tissue samples were used as controls. The tumor staging and grading was assessed by the team of urologists at Pathology Laboratory, Department of Urology, PIMS. The TNM system of staging was applied for evaluation of the tumor stage. The revised guidelines by National Comprehensive Cancer Network (NCCN) Clinical Practice Guidelines in Oncology (NCCN Guidelines $^{\circledR}$ ) for Bladder Cancer and American Society of Clinical Oncology (ACSO) 2015-2018 were followed during grading and staging of tumor samples (42).

Reverse transcription quantitative polymerase chain reaction $(R T-q P C R)$. Tissues extracted from the patients were stored in RNAlater ${ }^{\circledR}$ (Ambion; Thermo Fisher Scientific, Inc.) at $4^{\circ} \mathrm{C}$ in a refrigerator. RNA extraction was performed using TRIzol ${ }^{\circledR}$ (Invitrogen; Thermo Fisher Scientific, Inc.) reagent according to the manufacturer's protocol (43). Subsequently, cDNA synthesis was performed, followed by RNA quantification. The minimum concentration of RNA used in these experiments was 1-2 $\mu \mathrm{g}$ for cDNA synthesis. Thermo Scientific RevertAid First Strand cDNA Synthesis kit was used for cDNA synthesis (Thermo Fisher Scientific, Inc.), according to the manufacturer's protocols. The PrimerQuest tool (Integrated DNA Technologies, Inc.) was used to design the primers, which were subsequently altered manually to meet the required specifications for RT-qPCR. The forward primer for $\mathrm{Cav}-\mathrm{I}$ (NM_001753.4) was designed to span exon 2 and the junction with exon 3, and the reverse primer was selected from exon 3, whereas the primer set for DNM2 (NM_001005360.2) was designed based on the intron flanking exons 6 and 7 (Table I). Tubulin 3 was used as an endogenous marker for evaluating changes in the expression levels of Cav-1 and DNM2. In silico PCR (University of California Santa Cruz) was performed to ensure amplification of the 2 target genes. RT-qPCR using the Applied Biosystems ${ }^{\mathrm{TM}}$ StepOnePlus ${ }^{\mathrm{TM}}$ RealTime PCR system (Applied Biosystems, Inc.; Thermo Fisher Scientific, Inc.) was performed for the Cav-1 and DNM2 genes under standard conditions, as specified by the protocol. The concentration of cDNA was rounded up to $2 \mu \mathrm{g} / \mu \mathrm{l}$ for each sample, and the total volume per reaction was adjusted to $25 \mu \mathrm{l}$ with $\mathrm{SYBR}^{\mathrm{TM}}$ Green Master mix (Maxima Syber Green/ROX qPCR Master mix; Thermo Fisher Scientific, Inc.). The RT-qPCR conditions consisted of an initial incubation at $95^{\circ} \mathrm{C}$ for $10 \mathrm{~min}$, followed by 40 cycles of denaturation at $95^{\circ} \mathrm{C}$ for $30 \mathrm{sec}$, an annealing with primer at $57^{\circ} \mathrm{C}$ for $30 \mathrm{sec}$ and extension at $72^{\circ} \mathrm{C}$ for $30 \mathrm{sec}$. Final extension was performed at $72^{\circ} \mathrm{C}$ for $10 \mathrm{~min}$.
Gene expression analysis. The relative expression levels of $C a v-1$ and DNM2 were calculated using the $2^{-\Delta \Delta \mathrm{Cq}}$ method (44). Using $T U B B 3$ as the control reference gene (45), relative differences in gene expression were obtained in terms of the fold increase in expression. To obtain the expression data, the $\mathrm{C}_{\mathrm{q}}$ values of the $C a v-1$ and $D N M 2$ genes were normalized against the $\mathrm{C}_{\mathrm{q}}$ value for endogenous $T U B B 3$.

Statistical analysis. Statistical analyses were performed using GraphPad Prism 6 (GraphPad Software, Inc.) and OriginPro 2017 (OriginLab Corporation) software. Contingencies of the patients' data were determined using Fisher's exact two-tailed test, and the correlation between the gene expression patterns was assessed using Pearson's correlation coefficient test. Depending on the experiment, the statistical significance of the resulting data was determined using either the Wilcoxon test or one way analysis of variance followed by the Tukey's honest significant difference post-hoc test. $\mathrm{P}<0.05$ was considered to indicate a statistically significant difference.

\section{Results}

Tumor histopathology. Tumor staging was evaluated by the Pathology Laboratory of PIMS, according to the TNM system but incorporating the revisions of the NCCN Clinical Practice Guidelines in Oncology (NCCN Guidelines ${ }^{\circledR}$ ) for Bladder Cancer and ACSO 2015-2018 (42). Distribution of the tumor grade and stage data by sex and age groups was statistically analyzed (Table II). In October 2017, The Cancer Genome Atlas (TCGA) published the prevalence and incidence rates of bladder cancer (https://cancergenome.nih.gov/newsevents/newsannouncements/bladder-cancer_2017), which was increased in the male population compared with females, and, in terms of underlying causes, smoking was demonstrated to be the major factor in that study (46). A comprehensive molecular characterization study was also performed by TCGA research network, which described the genetic alterations associated with bladder cancer (24). In the present study, a significant difference was identified in terms of the pathology between the sexes in the different age groups ( $\mathrm{P}=0.0024$; Table II). A number of different diseases were identified in patients from both age groups, but their associations with bladder cancer were not statistically significant. Conversely, the risk factors of active smoking $(\mathrm{P}=0.0135)$ and passive smoking $(\mathrm{P}=0.0316)$ were identified to be significantly associated with bladder cancer (Table III). 
Table II. Tumor stage and grade data distribution by sex and age.

\begin{tabular}{|c|c|c|c|}
\hline \multirow[b]{2}{*}{ Patient data } & \multicolumn{2}{|c|}{ Age groups, years } & \multirow[b]{2}{*}{ P-value } \\
\hline & $\leq 50$ & $>50$ & \\
\hline \multicolumn{4}{|l|}{ Sex } \\
\hline Male & 32 & 15 & $0.0024^{\mathrm{a}}$ \\
\hline Female & 12 & 7 & \\
\hline \multicolumn{4}{|c|}{ Histology (\%) } \\
\hline \multicolumn{4}{|c|}{ Tumor grade } \\
\hline High & $20(45.4)$ & $12(55.0)$ & 0.6032 \\
\hline Low & $24(55.0)$ & $10(45.4)$ & \\
\hline \multicolumn{4}{|c|}{ Tumor stage } \\
\hline \multicolumn{4}{|l|}{ Stage I } \\
\hline Male & $16(50.0)$ & $4(27.1)$ & $0.0235^{\mathrm{a}}$ \\
\hline Female & $1 \quad(8.3)$ & $4(57.1)$ & \\
\hline \multicolumn{4}{|l|}{ Stage II } \\
\hline Male & $12(38)$ & $2(13.3)$ & $0.0441^{\mathrm{a}}$ \\
\hline Female & $1 \quad(8.3)$ & $3(42)$ & \\
\hline \multicolumn{4}{|c|}{ Stage III (\%) } \\
\hline Male & $4(12.5)$ & $9(60.0)$ & $0.0116^{\mathrm{a}}$ \\
\hline Female & $10(84.0)$ & $0(0.0)$ & \\
\hline
\end{tabular}

aP-value $<0.05$.

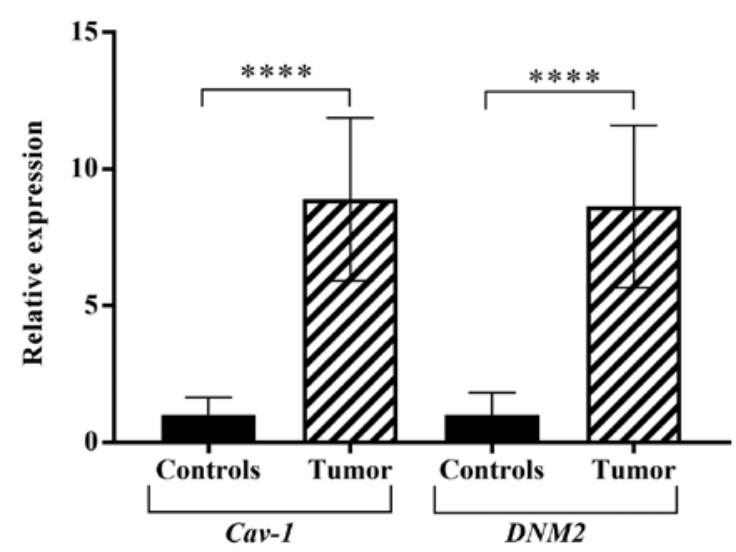

Figure 1. Comparison of Cav-1 and DNM2 expression in tumor and adjacent normal bladder tissues using the Wilcoxon test. ${ }^{* * * *} \mathrm{P}<0.0001$. Cav- 1 , caveolin-1; DNM2, dynamin-2.

Cav-1 and DNM2 expression. In the tumor samples, the expression levels of Cav-1 and DNM2 were experimentally analyzed using RT-qPCR. The expression of $\mathrm{Cav}-\mathrm{l}$ in the tumor samples was increased by 8.88 -fold overall compared with the normal tissues. Similarly, the expression level of DNM2 was also increased by 8.6 -fold compared with the normal adjacent, or control, tissues $(\mathrm{P}<0.001)$. As demonstrated in Fig. 1, boxplots of normalized (mean \pm standard error of the mean) gene expression of Cav-1 and DNM2 revealed a significant increase in gene expression in tumor tissues compared with the adjacent normal tissue. Previous studies also demonstrated increased expression levels of Cav-1 and DNM2 in different
Table III. Disease history and smoking habits in bladder cancer.

Age groups, years

\begin{tabular}{lll} 
Patient data $\quad \leq 50 \quad>50 \quad$ P-value \\
\hline
\end{tabular}

Sex

$\begin{array}{lrrr}\text { Male } & 32 & 15 & 0.0024^{\mathrm{b}} \\ \text { Female } & 12 & 7 & \end{array}$

Previous disease history $(\%)$

Hypertension

$\begin{array}{llllll}\text { Male } & 3 & (9.4) & 12 & (80.0) & 0.3781\end{array}$

Female

4 (33.3) $6 \quad(85.7)$

Diabetes mellitus

Male

Female

$\begin{array}{llll}5(16.0) & 7 & (47.0) & 0.6668\end{array}$

Urinary tract infections

Male

Female

$3(25.0) \quad 5 \quad(71.4)$

$\begin{array}{llll}4(12.5) & 5 & (33.3) & 0.6563\end{array}$

$6(50.0) \quad 4 \quad(57.1)$

Family bladder cancer

history

Male

Female

$\begin{array}{lllll}4(12.5) & 5 & (33.3) & 0.4909\end{array}$

$\begin{array}{llll}0 & (0.0) & 2 & (29.0)\end{array}$

Smoking

Male

Female

Actively smoking

Non-smoking

Smoke-free environment ${ }^{\mathrm{a}}$

Passive smoking

$\begin{array}{lllll}22(68.7) & 14 & (93.3) & 0.6327\end{array}$

2 (16.6) 5 (71.4)

$24(55.0) \quad 19 \quad(86.3) \quad 0.0135^{\mathrm{b}}$

$20(45.4) \quad 3 \quad(14.0)$

$15(75.0) \quad 0 \quad(0.0) \quad 0.0316^{\mathrm{b}}$

$5(25.0) \quad 3(100.0)$

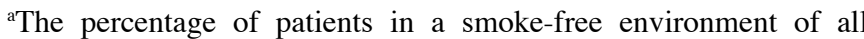
non-smoking patients. ${ }^{\text {bP-value }}<0.05$.

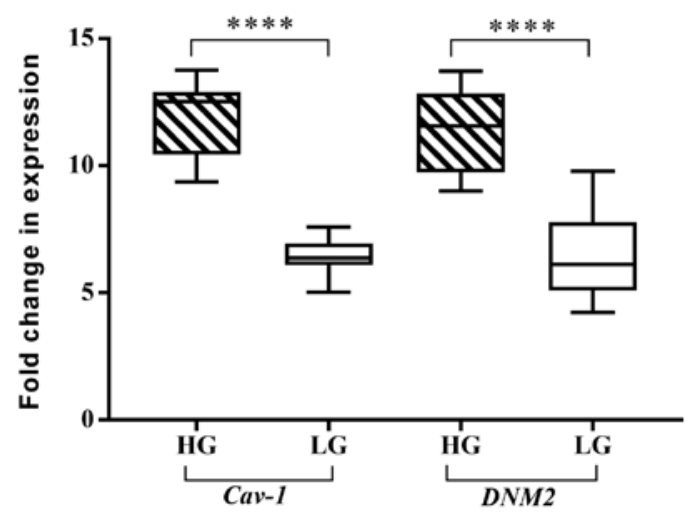

Figure 2. Comparison of Cav-1 and DNM2 expression in low- and high-grade tumor tissues using the Wilcoxon test. ${ }^{* * * *} \mathrm{P}<0.0001$. Cav-1, caveolin-1; DNM2, dynamin-2.

cancer cell lines $(39,41)$. The genes exhibited enhanced expression levels in bladder tumor samples concomitantly with the progression of cancer. A significant difference in expression levels was observed comparing between low- and high-grade tumors $(\mathrm{P}<0.0001$; Fig. 2$)$. A similar trend was 


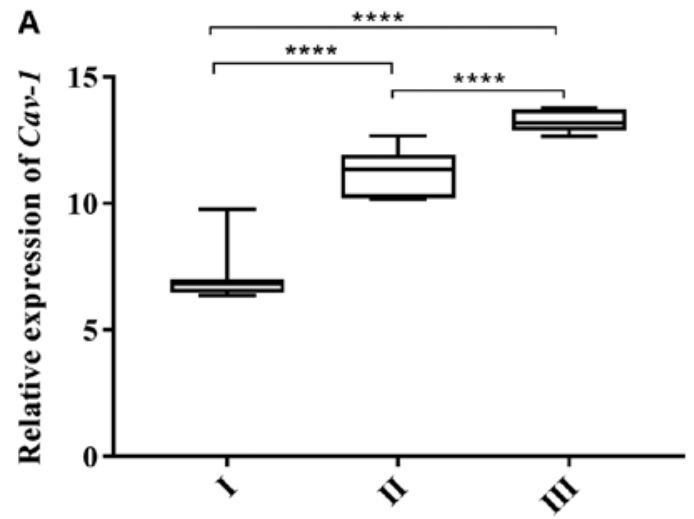

Tumor stages

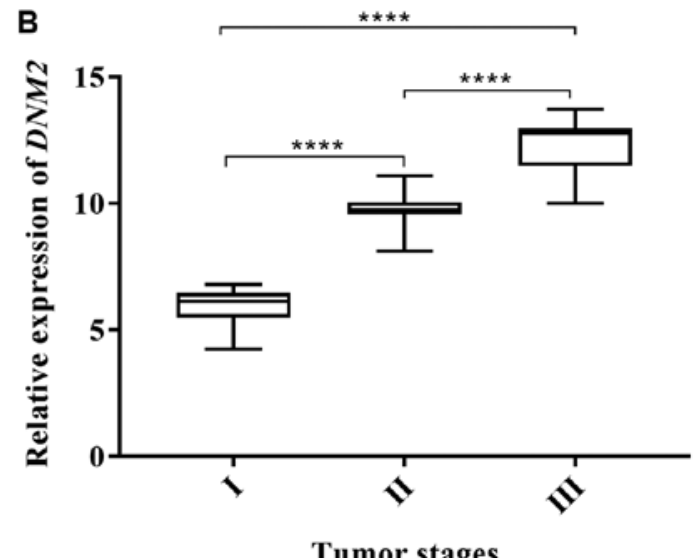

Tumor stages

Figure 3. Stage-wise comparison in the expression of (A) Cav-1 and (B) DNM2 in tumor samples. Overall statistical significance was determined using one way analysis of variance followed by Tukey's post-hoc test. ${ }^{* * * *} \mathrm{P}<0.0001$. Cav-1, caveolin-1; DNM2, dynamin-2.

A

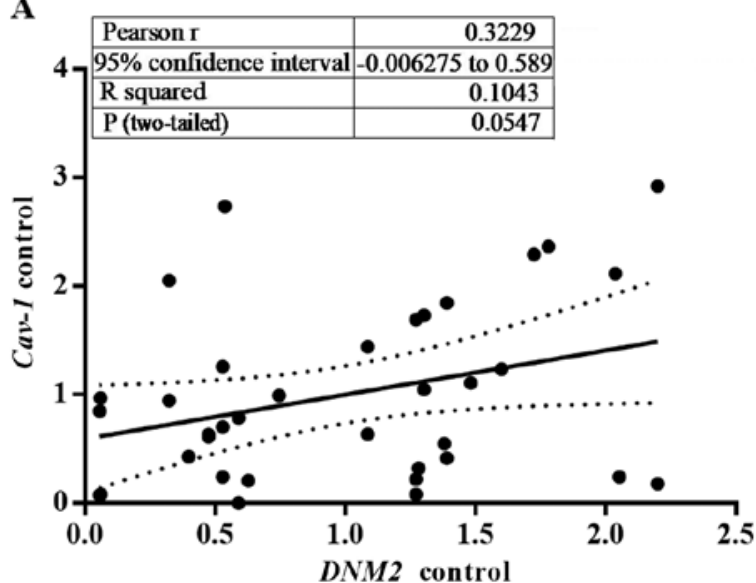

B

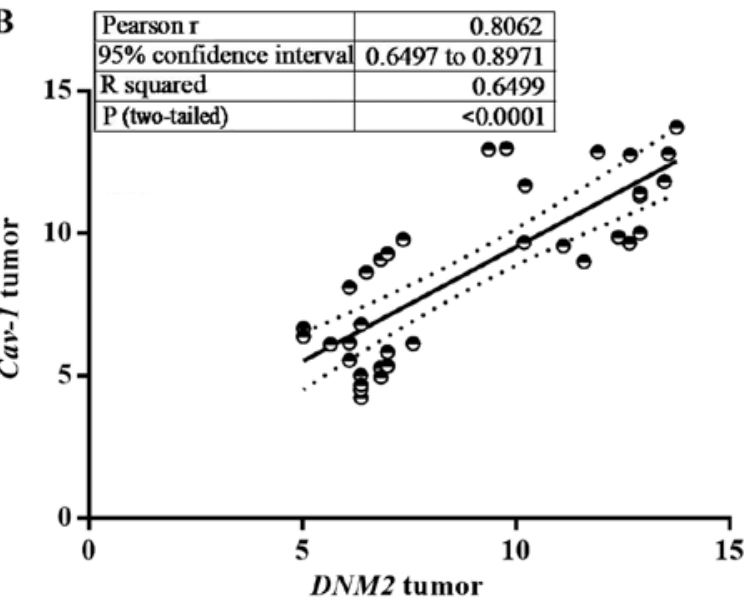

Figure 4. Correlation analysis of the expression levels of Cav-1 and DNM2 in (A) the adjacent normal bladder tissue ( $\mathrm{r}=0.32 ; \mathrm{P}=0.05)$ and $(\mathrm{B})$ the tumor samples $(\mathrm{r}=0.80 ; \mathrm{P}<0.0001)$. Cav-1, caveolin-1; DNM2, dynamin-2.

also observed with respect to the cancer stages. Alterations in Cav-1 and DNM2 expression were revealed to be associated with the cancer stage, as indicated in Fig. 3A and B. These results demonstrated that the expression levels of the two genes increased concomitantly with the development of higher disease stages. However, highly significant differences in the expression of Cav-1 and DNM2 were observed when stage I tumors were compared with stage II tumors $(\mathrm{P}<0.0001)$, and when stage II tissues were compared with stage III samples $(\mathrm{P}<0.0001)$. A similar difference was also identified when comparing stage I tumors with stage III tumors $(\mathrm{P}<0.0001$; Fig $3 \mathrm{~A}$ and $\mathrm{B})$.

Correlation between Cav-1 and DNM2. The Cav-1 and DNM2 genes serve an important role in the functionality of clathrin-independent endocytosis. Altered expression levels of the genes has been demonstrated to be associated with pathological outcomes $(32,47)$. In the present study, the expression of $C a v-1$ was clearly correlated with the expression of DNM2 $(\mathrm{P}<0.0001$; Pearson's coefficient, $\mathrm{r}=0.8617$; Fig. $4 \mathrm{~A}$ and $\mathrm{B})$. The segregation of DMN1/Cav-1 correlation data into two clusters additionally confirmed the increased expression of the 2 genes in high-grade tumors compared with low-grade tumors demonstrated in Fig. 2.

\section{Discussion}

Cav-1 is a key component of caveolae in terms of their formation, arrangement and function. Together with $D N M 2, \mathrm{Cav}-1$ initiates the process of endocytosis (32). Cav-1 has been demonstrated to be a critical component of numerous types of cancer, including breast, lung, colorectal, cervical and pancreatic cancer (21,48-50). Previous studies have presented accumulating evidence revealing that cancer cells are prone to modifying the microenvironment of the tumor, inducing the adjacent cells to become malignant (51-54). In this regard, Cav-1 is implicated as an important protein that affects the metabolic activity of cells during cancer progression (55). The results of the present study revealed a progressive increase in the expression level of $\mathrm{Cav}-1$ concomitant with the higher stages of bladder cancer. As the stage of bladder cancer progresses, cells that are cancerous maintain their survival by utilizing key proteins that provide them with the necessarily favorable environment to grow, invade and migrate via regulating the 
respective functional proteins. Increased expression levels of Cav-1 in higher grades of bladder cancer enable an increased potential of the cells to invade and proliferate (56). Therefore, in the present study, the high-grade tumors were revealed to have comparatively enhanced expression levels of Cav-1 compared with low-grade tumors.

Altered expression of DNM2 also serves a role in cancer progression. DNM2 has been implicated as a therapeutic target for cervical cancer: In Hela cells, dynamin-2 inhibitors have been demonstrated to cause decreased migration and invasion via decreasing the expression of matrix metallopeptidase 9, thereby lowering the rate of cell proliferation (57). Similar to $C a v-1$, an increase in the expression of DNM2 has been demonstrated to correspond to advances in the tumor stage (19). In the present study, the expression levels of DNM2 and Cav-1 genes exhibited a marked correlation with the progression of bladder tumor stage. These results demonstrated that an increase in the expression of these 2 genes may stimulate the tumors to proliferate, invade and metastasize to different adjacent organs. Cancer cells have their own modified microenvironment through which they communicate with adjacent cells for growth proliferation and survival (5).

Summarizing what is known concerning cancer progression, cellular communication is the hallmark of tumorigenesis. Interactions with signaling molecules provide a major focus for disrupted signaling. Cav-1, being a key protein of the caveolae, is critical for cancer development, as it directly interacts with signaling proteins, including phosphoinositide 3-kinase, Src, phospholipases, extracellular signal-regulated kinase, G-proteins, endothelial nitric oxide synthase, adenylyl cyclase, protein kinase C, p53 and cell division control protein 42 homolog, and is involved in signal transduction cascades $(13,58,59)$. Dysfunction of $C a v-1$, resulting from the aberrant expression of the gene, triggers the activation of various growth-promoting pathways $(4,11)$. Previous studies have suggested overexpression of $\mathrm{Cav}-1$ to be a cause of cancer progression $(32,60,61)$. Similarly, together with Cav-1, DNM2 also mediates effects on cancer formation and progression. The 2 proteins are involved in the endocytosis of a number of receptor proteins, ligands and signaling molecules $(19,62)$. However, it has been suggested that there are several other interlinked signaling pathways that, in response to overexpression of $C a v-1$ and $D N M 2$, may be activated and/or deactivated, resulting in tumor formation (63).

Although the present study has described the genetic expression of the target genes, there were several limitations. Firstly, the samples were not obtained from stages $0 \mathrm{a}$ and 0 is, the 2 preliminary stages of bladder cancer, or the final stage, stage IV, as patients are not subjected to TURBT at the initial or the last stages of disease. Consequently, all the patients within the study cohort were diagnosed with mid-stage disease, for which TURBT surgery is available. There is an urgent requirement for diagnoses of bladder cancer at early stages. The target genes selected for the present study may be considered as good prognostic marker for bladder cancer. If bladder tumor samples from the initial to the final stages had been available for analysis, then the differences in expression of the target genes in the tumor samples could have been validated more comprehensively. Future studies will aim to investigate the protein expression of the target genes in bladder tumor samples, and to explore the functional disruptions due to overexpression of the target genes/proteins that may have caused tumor aggressiveness during cancer progression. In the present study, the observed association of the increased expression levels of $C a v-1$ and DNM2 with advancing tumor stage could be considered as a risk factor for bladder cancer, which may additionally aid tumor and disease prognosis, and provide potentially novel treatment options.

\section{Acknowledgements}

Not applicable.

\section{Funding}

The present study was supported by the COMSATS Research Grant Program (grant no. 16/54/CRGP/CIIT/IBD/15/791) by COMSATS University Islamabad.

\section{Availability of data and materials}

All data generated or analyzed during this study are included in this published article.

\section{Authors' contributions}

SAR was responsible for conception and design of the study, performed the data analysis and its interpretation, and prepared the manuscript. STAS refined the research design, and performed data analysis and interpretation. KS assisted with the experimental protocols and data acquisition. AY, AK, $\mathrm{MN}$ and AM evaluated the tumor samples and prepared the histopathological reports of the tumors. AT and NB contributed towards the research design, and secured collaborations with the hospitals from which the samples were obtained. MJK and AH also assisted with the conception of the study, and with research supervision.

\section{Ethics approval and consent to participate}

The study was approved by the ethical review board of COMSATS Institute of Information Technology (approval no. CIIT/Bio/ERB/18/76). Written signed consent was obtained from the patients involved.

\section{Patient consent for publication}

Written signed consent was obtained from the patients involved.

\section{Competing interests}

The authors declare that they have no competing interests.

\section{References}

1. Bastiani M and Parton RG: Caveolae at a glance. J Cell Sci 123: 3831-3836, 2010.

2. Anderson RG: The Caveolae membrane system. Annu Rev Biochem 67: 199-225, 1998. 
3. Yamada E: The fine structure of the gall bladder epithelium of the mouse. J Biophys Biochem Cytol 1: 445-458, 1955.

4. Cheng JPX and Nichols BJ: Caveolae: One function or many? Trends Cell Biol 26: 177-189, 2016.

5. Martinez-Outschoorn UE, Sotgia F and Lisanti MP: Caveolae and signalling in cancer. Nat Rev Cancer 15: 225-237, 2015.

6. Parton RG and Pozo MA: Caveolae as plasma membrane sensors, protectors and organizers. Nat Rev Mol Cell Biol 14: 98-112, 2013.

7. Ludwig A, Howard G, Mendoza-Topaz C, Deerinck T, Mackey M, Sandin S, Ellisman MH and Nichols BJ: Molecular composition and ultrastructure of the caveolar coat complex. PLoS Biol 11: e1001640, 2013.

8. Patel HH, Murray F and Insel PA: Caveolae as organizers of pharmacologically relevant signal transduction molecules. Annu Rev Pharmacol Toxicol 48: 359-391, 2008.

9. Yao Q, Chen J, Cao H, Orth JD, McCaffery JM, Stan RV and McNiven MA: Caveolin-1 interacts directly with dynamin-2. J Mol Biol 348: 491-501, 2005.

10. Mayor S, Parton RG and Donaldson JG: Clathrin-independent pathways of endocytosis. Cold Spring Harb Perspect Biol 6 : a016758, 2014.

11. Liu P, Rudick M and Anderson RG: Multiple functions of caveolin-1. J Biol Chem 277: 41295-41298, 2002.

12. Urra H, Torres VA, Ortiz RJ, Lobos L, Díaz MI, Díaz N, Härtel S, Leyton L and Quest A: Caveolin-1-enhanced motility and focal adhesion turnover require tyrosine-14 but not accumulation to the rear in metastatic cancer cells. PLoS One 7: e33085, 2012

13. Chatterjee M, Ben-Josef E, Thomas DG, Morgan MA, Zalupski MM, Khan G, Andrew Robinson C, Griffith KA, Chen CS, Ludwig T, et al: Caveolin-1 is associated with tumor progression and confers a multi-modality resistance phenotype in pancreatic cancer. Sci Rep 5: 10867, 2015.

14. Hinshaw JE: Dynamin and its role in membrane fission. Annu Rev Cell Dev Biol 16: 483-519, 2000.

15. Normanno N, De Luca A, Bianco C, Strizzi L, Mancino M Maiello MR, Carotenuto A, De Feo G, Caponigro F and Salomon DS: Epidermal growth factor receptor (EGFR) signaling in cancer. Gene 366: 2-16, 2006.

16. Basu Roy UK, Rial NS, Kachel KL and Gerner EW: Activated K-RAS increases polyamine uptake in human colon cancer cells through modulation of caveolar endocytosis. Mol Carcinog 47: 538-553, 2008

17. Feng H, Liu KW, Guo P, Zhang P, Cheng T, McNiven MA, Johnson GR, Hu B and Cheng SY: Dynamin 2 mediates PDGFRalpha-SHP-2-promoted glioblastoma growth and invasion. Oncogene 31: 2691-2702, 2012.

18. Eppinga RD, Krueger EW, Weller SG, Zhang L, Cao H and McNiven MA: Increased expression of the large GTPase dynamin 2 potentiates metastatic migration and invasion of pancreatic ductal carcinoma. Oncogene 31: 1228-1241, 2012.

19. Meng J: Distinct functions of dynamin isoforms in tumorigenesis and their potential as therapeutic targets in cancer. Oncotarget 8 : 41701-41716, 2017

20. Alshenawy HA and Ali MA: Differential caveolin-1 expression in colon carcinoma and its relation to E-cadherin-beta-catenin complex. Ann Diagn Pathol 17: 476-482, 2013.

21. Patlolla JM, Swamy MV, Raju J and Rao CV: Overexpression of caveolin-1 in experimental colon adenocarcinomas and human colon cancer cell lines. Oncol Rep 11: 957-963, 2004

22. Tanase CP: Caveolin-1: A marker for pancreatic cancer diagnosis. Expert Rev Mol Diagn 8: 395-404, 2008.

23. Sarwar MR and Saqib A: Cancer prevalence, incidence and mortality rates in Pakistan in 2012. Cogent Med 4: 1288773 , 2017.

24. Robertson AG, Kim J, Al-Ahmadie H, Bellmunt J, Guo G Cherniack AD, Hinoue T, Laird PW, Hoadley KA, Akbani R, et al: Comprehensive molecular characterization of muscle-invasive bladder cancer. Cell 171: 540-556.e525, 2017.

25. Zhang $X$ and Zhang Y: Bladder cancer and genetic mutations Cell Biochem Biophys 73: 65-69, 2015.

26. Wang K, Liu T, Liu C, Meng Y, Yuan X, Liu L, Ge N, Liu J, Wang $\mathrm{C}$, Ren $\mathrm{H}$, et al: TERT promoter mutations and TERT mRNA but not FGFR3 mutations are urinary biomarkers in Han Chinese patients with urothelial bladder cancer. Oncologist 20: 263-269, 2015

27. Zhao M, He XL and Teng XD: Understanding the molecular pathogenesis and prognostics of bladder cancer: An overview. Chin J Cancer Res 28: 92-98, 2016.
28. Rosenblatt R, Jonmarker S, Lewensohn R, Egevad L, Sherif A, Kälkner KM, Nilsson S, Valdman A and Ullén A: Current status of prognostic immunohistochemical markers for urothelial bladder cancer. Tumour Biol 29: 311-322, 2008.

29. Sever R and Brugge JS: Signal transduction in cancer. Cold Spring Harb Perspect Med 5: a006098, 2015.

30. Massey KA and Schnitzer JE: Caveolae and cancer. Recent Results Cancer Res 180: 217-231, 2010.

31. Gupta R, Toufaily C and Annabi B: Caveolin and cavin family members: Dual roles in cancer. Biochimie 107: 188-202, 2014.

32. Chen D and Che G: Value of caveolin-1 in cancer progression and prognosis: Emphasis on cancer-associated fibroblasts, human cancer cells and mechanism of caveolin-1 expression (review). Oncol Lett 8: 1409-1421, 2014.

33. Soria F, Lucca I, Moschini M, Mathieu R, Rouprêt M, Karakiewicz PI, Briganti A, Rink M, Gust KM, Hassler MR, et al: Caveolin-1 as prognostic factor of disease recurrence and survival in patients treated with radical cystectomy for bladder cancer. Urol Oncol 35: 356-362, 2017.

34. Sanchez-Carbayo M, Socci ND, Lozano J, Saint F and Cordon-Cardo C: Defining molecular profiles of poor outcome in patients with invasive bladder cancer using oligonucleotide microarrays. J Clin Oncol 24: 778-789, 2006.

35. Rosser CJ, Liu L, Sun Y, Villicana P, McCullers M, Porvasnik S, Young PR, Parker AS and Goodison S: Bladder cancer-associated gene expression signatures identified by profiling of exfoliated urothelia. Cancer Epidemiol Biomarkers Prev 18: 444-453, 2009.

36. Dyrskjot L, Zieger K, Kruhoffer M, Thykjaer T, Jensen JL, Primdahl H, Aziz N, Marcussen N, Møller K and Orntoft TF: A molecular signature in superficial bladder carcinoma predicts clinical outcome. Clin Cancer Res 11: 4029-4036, 2005.

37. Gershenwald JE, Scolyer RA, Hess KR, Sondak VK, Long GV, Ross MI, Lazar AJ, Faries MB, Kirkwood JM, McArthur GA, et al: Melanoma staging: Evidence-based changes in the American Joint Committee on cancer eighth edition cancer staging manual. CA Cancer J Clin 67: 472-492, 2017.

38. Pan CC and Chang YH: The 2004 World Health Organization/ International Society of Urological Pathology classification system for non-muscle-invasive bladder cancer. Urol Sci 24: 96-100 2013

39. Zhang Y, Nolan M, Yamada H, Watanabe M, Nasu Y, Takei K and Takeda T: Dynamin2 GTPase contributes to invadopodia formation in invasive bladder cancer cells. Biochem Biophys Res Commun 480: 409-414, 2016

40. Ruan J and Weng ZL: Analysis of the relationship between expression of caveolin-1 and prognosis in bladder transitional cell carcinoma. Zhonghua Zhong Liu Za Zhi 32: 429-431, 2010 (In Chinese)

41. Liang W, Hao Z, Han JL, Zhu DJ, Jin ZF and Xie WL: CAV-1 contributes to bladder cancer progression by inducing epithelial-to-mesenchymal transition. Urol Oncol 32: 855-863, 2014.

42. Spiess PE, Agarwal N, Bangs R, Boorjian SA, Buyyounouski MK, Clark PE, Downs TM,Efstathiou JA, Flaig TW,Friedlander T, et al: Bladder cancer, version 5.2017, NCCN clinical practice guidelines in oncology. J Natl Compr Canc Netw 15: 1240-1267, 2017.

43. Rio DC, Ares M Jr, Hannon GJ and Nilsen TW: Purification of RNA using TRIzol (TRI reagent). Cold Spring Harb Protoc 2010: pdb.prot5439, 2010.

44. Livak KJ and Schmittgen TD: Analysis of relative gene expression data using real-time quantitative PCR and the 2(-Delta Delta C(T)) method. Methods 25: 402-408, 2001.

45. Bangaru ML, Park F, Hudmon A, McCallum JB and Hogan QH Quantification of gene expression after painful nerve injury: Validation of optimal reference genes. J Mol Neurosci 46: 497-504, 2012.

46. Cancer. Net Editorial Board: Bladder Cancer-Risk Factors https://www.cancer.net/cancer-types/bladder-cancer/risk-factors Accessed: June 25, 2012.

47. Aghbolaghi AG and Lechpammer M: A rare case of centronuclear myopathy with DNM2 mutation: Genotype-phenotype correlation. Autops Case Rep 7: 43-48, 2017.

48. Duregon E, Senetta R, Bertero L, Bussolati B, Annaratone L, Pittaro A, Papotti M, Marchiò C and Cassoni P: Caveolin 1 expression favors tumor growth and is associated with poor survival in primary lung adenocarcinomas. Tumour Biol 39: $1010428317694311,2017$.

49. Lee SW, Reimer CL, Oh P, Campbell DB and Schnitzer JE: Tumor cell growth inhibition by caveolin re-expression in human breast cancer cells. Oncogene 16: 1391-1397, 1998. 
50. Lin M, DiVito MM, Merajver SD, Boyanapalli $M$ and van Golen KL: Regulation of pancreatic cancer cell migration and invasion by RhoC GTPase and Caveolin-1. Mol Cancer 4: 21, 2005.

51. Friedl P and Alexander S: Cancer invasion and the microenvironment: Plasticity and reciprocity. Cell 147: 992-1009, 2011

52. Kang HW, Kim WJ and Yun SJ: The role of the tumor microenvironment in bladder cancer development and progression. Transl Cancer Res 6 (Suppl): S744-S758, 2017.

53. Sotgia F, Martinez-Outschoorn UE, Howell A, Pestell RG Pavlides S and Lisanti MP: Caveolin-1 and cancer metabolism in the tumor microenvironment: Markers, models, and mechanisms. Annu Rev Pathol 7: 423-467, 2012.

54. Wang M, Zhao J, Zhang L, Wei F, Lian Y, Wu Y, Gong Z, Zhang S, Zhou J, Cao K, et al: Role of tumor microenvironment in tumorigenesis. J Cancer 8: 761-773, 2017.

55. Nwosu ZC, Ebert MP, Dooley S and Meyer C: Caveolin-1 in the regulation of cell metabolism: A cancer perspective. Mo Cancer 15: 71, 2016.

56. Diaz-Valdivia N, Bravo D, Huerta H, Henriquez S, Gabler F, Vega M, Romero C, Calderon C, Owen GI, Leyton L and Quest AF: Enhanced caveolin-1 expression increases migration, anchorage-independent growth and invasion of endometrial adenocarcinoma cells. BMC Cancer 15: 463, 2015.

57. Girard E, Paul JL, Fournier N, Beaune P, Johannes L, Lamaze $\mathrm{C}$ and Védie B: The Dynamin Chemical Inhibitor Dynasore Impairs Cholesterol Trafficking and Sterol-Sensitive Genes Transcription in Human HeLa Cells and Macrophages. PLoS One 6: e29042,2011.
58. Lee YY, Jeon HK, Lee J, Do IG, Choi CH, Kim TJ, Kim BG, Bae DS, Kim YC and Lee JW: Dynamin 2 inhibitors as novel therapeutic agents against cervical cancer cells. Anticancer Res 36: 6381-6388, 2016.

59. Galbiati F, Volonte D, Liu J, Capozza F, Frank PG, Zhu L, Pestell RG and Lisanti MP: Caveolin-1 expression negatively regulates cell cycle progression by inducing $\mathrm{G}(0) / \mathrm{G}(1)$ arrest via a p53/p21(WAF1/Cip1)-dependent mechanism. Mol Biol Cell 12: 2229-2244, 2001.

60. Nunez-Wehinger S, Ortiz RJ, Diaz N, Diaz J, Lobos-Gonzalez L and Quest AF: Caveolin-1 in cell migration and metastasis. Curr Mol Med 14: 255-274, 2014.

61. Sun DS, Hong SA, Won HS, Yoo SH, Lee HH, Kim O and Ko YH: Prognostic value of metastatic tumoral caveolin-1 expression in patients with resected gastric cancer. Gastroenterol Res Pract 2017: 5905173, 2017.

62. Ge Z, Gu Y, Han Q, Zhao G, Li M, Li J, Chen B, Sun T, Dovat S, Gale RP and Song C: Targeting HIGH DYNAMIN-2 (DNM2) expression by restoring ikaros function in acute lymphoblastic leukemia. Sci Rep 6: 38004, 2016.

63. Quest AF, Gutierrez-Pajares JL and Torres VA: Caveolin-1: An ambiguous partner in cell signalling and cancer. J Cell Mol Med 12: 1130-1150, 2008. 